\title{
A New Configurational Analysis of 1,6,7-triacetoxy-8,13-epoxy-14-labden- 11-one Isolated from Plectranthus ornatus Based on NMR and Theoretical Calculations
}

\author{
Patrícia M. Oliveira, Alison G. Pacheco, Rosemeire B. Alves, Dorila Piló-Veloso, Délio S. Raslan \\ and Antônio F. de Carvalho Alcântara*
}

Departamento de Química, ICEx, Universidade Federal de Minas Gerais, Belo Horizonte 31270-901 - MG, Brazil

\begin{abstract}
This work describes the configurational and conformational analyses of 1,6,7-triacetoxy-8,13-epoxy-14-labden11-one, a labdane diterpenoid isolated from Plectranthus ornatus. Its relative stereochemistry was previously proposed by comparison with ${ }^{1} \mathrm{H}$ and ${ }^{13} \mathrm{C}$ NMR data of forskolin (2); however, the configurations of $\mathrm{C}-8$ and $\mathrm{C}-13$ have not been confirmed. Correlations between ${ }^{13} \mathrm{C}$ NMR experimental data and HF/6-31G* calculated values of carbon chemical shifts were performed for configurational and conformational analyses. This procedure was formerly applied to the configurational analysis of $\mathbf{2}$. Among the seven different forskolin-type structures investigated, the ${ }^{13} \mathrm{C}$ NMR data of 2 correlated best with those with the same stereochemistry of $\mathbf{2}$ described in the literature. Thus, the same procedure was considered valid for configurational analysis of the labdane diterpenoid isolated from $P$. ornatus. The relative stereochemistry of this compound based on theoretical calculations was similar to the structure previously proposed, but the best results were obtained considering configurational inversion at $\mathrm{C}-13$.
\end{abstract}

Keywords: Plectranthus ornatus, labdane diterpenoid, configurational analysis by NMR data, HF and DFT theoretical calculations, carbon chemical shift calculations.

\section{INTRODUCTION}

Plectranthus ornatus Codd. (Lamiaceae) is popularly used in Brazil to treat digestive problems as a substitute of species P. barbatus [1]. Previous studies on the secondary metabolites of $P$. ornatus Codd. (syn.: Coleus comosus Hochst. Ex Gürke) reported the isolation of labdane and clerodane derivatives $[2,3]$. A labdane diterpenoid structure belonging to the normal-labdane series according to NMR analyses was previously isolated from $P$. ornatus [2]. Structure 1 was proposed for this labdane diterpenoid considering the stereochemistry of forskolin (2) and related diterpenoids (Fig. 1) [4]. The last compound was isolated from P. barbatus Andr. (syn.: Coleus barbatus and Coleus forskohlii Briq.), which shows a diversity of pharmacological properties related to the activation of adenyl cyclase, thus, modulating cAMP levels [5]. For example, the activation of adenyl cyclase can stimulate gastric secretions and the presence of 2 in $P$. barbatus may explain its use in the popular treatment of digestive disorders.

Although the $1 \mathrm{D}\left({ }^{1} \mathrm{H}\right.$ and $\left.{ }^{13} \mathrm{C}\right)$ and $2 \mathrm{D}\left({ }^{1} \mathrm{H}-{ }^{1} \mathrm{H} \mathrm{COSY},{ }^{1} \mathrm{H}-\right.$ ${ }^{13} \mathrm{C}$ HSQC, and ${ }^{1} \mathrm{H}-{ }^{13} \mathrm{C}$ HMBC) NMR analyses of the labdane diterpenoid isolated from $P$. ornatus are in agreement for $\mathbf{1}$, the configurations of $\mathrm{C}-8$ and $\mathrm{C}-13$ have not been confirmed. The stereochemistry of the forskolin derivatives is normally deduced by NOESY experiment [6-9] and the exciton chirality circular dichroism method [6]. The $R$ configuration of $\mathrm{C}-13$ in these forskolin-type skeletons was confirmed

*Address correspondence to this author at the Departamento de Química, ICEx, UFMG. Av. Presidente Antônio Carlos, 6627, Pampulha, CEP 31270901, Belo Horizonte - MG, Brazil; E-mail: aalcantara@zeus.qui.ufmg.br by NOESY experiments based on correlations between the signals attributed to H-16 and H-17. However, in the case of the labdane diterpenoid isolated from $P$. ornatus, NOESY correlations between $\mathrm{H}-16$ and $\mathrm{H}-17$ were not observed. The signal at $\delta_{\mathrm{H}} 1.52(\mathrm{H}-17)$ shows NOESY correlations only with the signal at $\delta_{\mathrm{H}} 2.66-2.60\left(\mathrm{H}-12_{\alpha} / \mathrm{H}-12_{\beta}\right)$. The signal at $\delta_{\mathrm{H}} 1.23(\mathrm{H}-16)$ shows NOESY correlations only with the signals at $\delta_{\mathrm{H}} 2.66-2.60$ and $5.95(\mathrm{H}-14)$ [2].

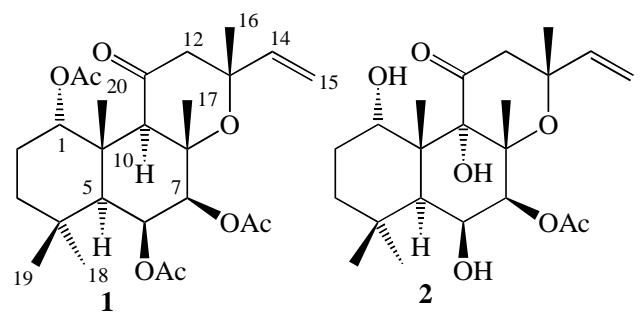

Fig. (1). Chemical structure previously proposed to the labdane diterpenoid isolated from $P$. ornatus (1) based on the stereochemistry of forskolin (2).

Therefore, the present work describes the configurational and conformational analyses of the labdane diterpenoid isolated from $P$. ornatus based on correlations between ${ }^{13} \mathrm{C}$ NMR data and calculated carbon chemical shift values. Geometry optimizations and carbon chemical shift calculations were performed using HF [10] and DFT [11] methods. This procedure has been efficiently employed in the structural determination of diterpenoids [12] and other organic compounds $[13,14]$. Correlations between calculated and experimental chemical shifts from ${ }^{13} \mathrm{C}$ NMR data of 2 were considered a validation criterion of this procedure in the con- 
figurational determination of the labdane diterpenoid isolated from P. ornatus.

\section{MATERIALS AND METHODOLOGY}

Theoretical studies were carried out using software package GAUSSIAN03 [15]. Spatial arrangements determined by NMR data were used as initial models in geometry optimization calculations. HF and DFT geometry optimizations were performed using the geometries previously obtained by the PM3 semi-empirical method [16]. BLYP functional with standard Pople's split valence $6-31 G^{*}$ base set [17-21] was used in DFT calculations. The optimized geometries were characterized as true minima on the potential energy surface (PES) when all harmonic frequencies were real. The electronic-nuclear energies $(E)$ were calculated by HF and DFT methods. HF/6-31G* and DFT/BLYP/6-31G* optimized geometries were used in carbon chemical shift calculations at the same levels of theory. Calculated carbon chemical shifts $\left(\sigma_{\mathrm{C}}\right)$ were obtained in relation to the corresponding HF/631G* and DFT/BLYP/6-31G* calculated values for tetramethylsilane ( $\sigma_{\mathrm{C}} 208.21$ and 186.8 , respectively).

Correlations between $\sigma_{\mathrm{C}}$ values and experimental carbon chemical shifts $\left(\delta_{\mathrm{C}}\right)$ were obtained using software package Origin $^{\mathrm{TM}}$ Standard $7.5 ; \sigma_{\mathrm{C}}$ and $\delta_{\mathrm{C}}$ values were plotted on the $x$ and $y$ axes, respectively. Correlation curves were given as linear fits with correlation coefficients $\left(\mathrm{R}^{2}\right)$ and standard deviations (SD) furnished by the program.

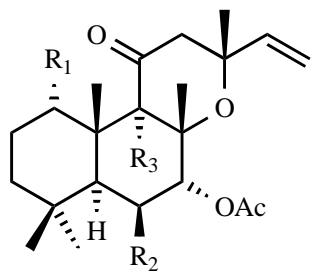

1 (C7): $\mathrm{R}_{1}=\mathrm{R}_{2}=\mathrm{OAc} ; \mathrm{R}_{3}=\mathrm{H}$

2 (C7): $\mathrm{R}_{1}=\mathrm{R}_{2}=\mathrm{R}_{3}=\mathrm{OH}$

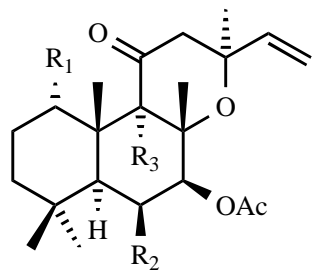

1 (C13): $\mathrm{R}_{1}=\mathrm{R}_{2}=\mathrm{OAc} ; \mathrm{R}_{3}=\mathrm{H}$

2 (C13): $\mathrm{R}_{1}=\mathrm{R}_{2}=\mathrm{R}_{3}=\mathrm{OH}$

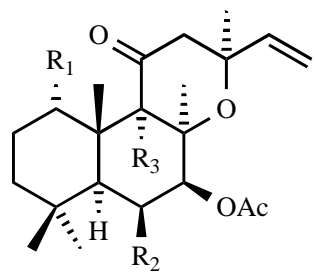

$1\left(\right.$ C8,C13): $\mathrm{R}_{1}=\mathrm{R}_{2}=\mathrm{OAc} ; \mathrm{R}_{3}=\mathrm{H}$

2 (C8,C13): $\mathrm{R}_{1}=\mathrm{R}_{2}=\mathrm{R}_{3}=\mathrm{OH}$

\section{RESULTS AND DISCUSSION}

Initially, HF/6-31G* and DFT/BLYP/6-31G* geometry optimizations for structures in the gaseous phase were carried out for 2 and its six configurational derivatives at $\mathrm{C}-7$, C-8, and C-13 (Fig. 2). Structures 2(C7,C8,C13) and $2(\mathbf{C 8 , C 1 3 )}$ have the highest and lowest energies, respectively (Table 1). The energy difference between these structures $(\Delta E=8.50 \mathrm{kcal} / \mathrm{mol})$ is very small and all structures are thermodynamically probable. All structures present rings A and $\mathrm{B}$ in the chair conformation, ring conjunction as transform for $\mathrm{A} / \mathrm{B}$, and stabilized by a hydrogen bond between the hydrogen of the hydroxyl group at C-9 and the oxygen at C-1.

Structures 2, 2(C7), 2(C7,C13), and 2(C13) show ring C as a chair conformation with lower energy in relation to the boat conformation $\left(\Delta E=E_{\text {(chair) }}-E_{\text {(boat) }}<-1.0 \mathrm{kcal} / \mathrm{mol}\right)$. On the other hand, 2(C8), 2(C8,C13), and 2(C7,C8,C13) show ring $\mathrm{C}$ in a boat conformation and present a higher energy difference in relation to the one in chair conformation $(\Delta E=$ $\left.E_{\text {(boat) }}-E_{\text {(chair) }} \sim-4.5 \mathrm{kcal} / \mathrm{mol}\right)$. As a result, the structures with configurational inversion of $\mathrm{C}-8$ show ring $\mathrm{C}$ in a boat conformation, ring conjunction as cis-form for $\mathrm{B} / \mathrm{C}$, and $\mathrm{C}$ 17 is in the equatorial position on ring $\mathrm{B}$. There is a hydrogen bond between the hydroxyl group at C-6 and the oxygen atoms of the acetate group at $\mathrm{C}-7$ in $2,2(\mathrm{C8}), 2(\mathrm{C13})$, and 2(C8,C13). As 2(C8) and 2(C8,C13) show the highest en-

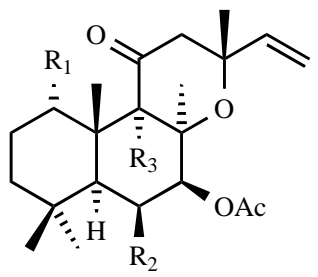

1 (C8): $\mathrm{R}_{1}=\mathrm{R}_{2}=\mathrm{OAc} ; \mathrm{R}_{3}=\mathrm{H}$

2 (C8): $\mathrm{R}_{1}=\mathrm{R}_{2}=\mathrm{R}_{3}=\mathrm{OH}$

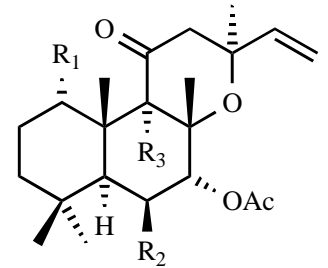

$1\left(\right.$ C7,C13): $\mathrm{R}_{1}=\mathrm{R}_{2}=\mathrm{OAc} ; \mathrm{R}_{3}=\mathrm{H}$

2 (C7,C13): $\mathrm{R}_{1}=\mathrm{R}_{2}=\mathrm{R}_{3}=\mathrm{OH}$

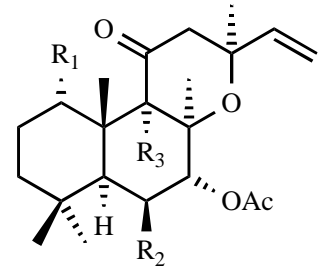

$1\left(\right.$ C7,C8,C13): $\mathrm{R}_{1}=\mathrm{R}_{2}=\mathrm{OAc} ; \mathrm{R}_{3}=\mathrm{H}$

$2(\mathrm{C} 7, \mathrm{C} 8, \mathrm{C13}): \mathrm{R}_{1}=\mathrm{R}_{2}=\mathrm{R}_{3}=\mathrm{OH}$

Fig. (2). Chemical structure of derivatives of $\mathbf{1}$ and 2, including the new relative configuration determined for labdane diterpenoid isolated from P. ornatus, $\mathbf{1}(\mathbf{C 1 3})$. 
Table 1. Electronic-Nuclear Energies $(E)$ of the Optimized Geometries of 2 and its Configurational Derivatives, Including Values of Linear Fit $\left(\mathbf{R}^{2}\right)$ and Standard Deviation (SD) Obtained for the Correlations Between ${ }^{13} \mathrm{C}$ NMR Data of 2 and their Calculated Carbon Chemical Shifts (HF/6-31G* Calculations Performed for Structures in the Gaseous Phase)

\begin{tabular}{|c|c|c|c|}
\hline Structure & $\boldsymbol{E}$ (in Hartree) & $\mathbf{R}^{\mathbf{2}}$ & SD \\
\hline \hline $\mathbf{2}$ & -1376.87459459 & 0.9971 & 3.89 \\
\hline $\mathbf{2 ( C 7 )}$ & -1376.87303568 & 0.9963 & 4.41 \\
\hline $\mathbf{2 ( C 8 )}$ & -1376.86957667 & 0.9969 & 4.06 \\
\hline $\mathbf{2 ( C 1 3 )}$ & -1376.87732036 & 0.9966 & 4.79 \\
\hline $\mathbf{2 ( C 7 , C 1 3 )}$ & -1376.87550541 & 0.9957 & 5.08 \\
\hline $\mathbf{2 ( C 8 , C 1 3 )}$ & -1376.86391870 & 0.9951 & 5.08 \\
\hline $\mathbf{2 ( C 7 , C 8 , C 1 3 )}$ & -1376.87746603 & 0.9953 & \\
\hline
\end{tabular}

ergy values in Table $\mathbf{1}$, this hydrogen bond is not a significant interaction in their conformational analyses.

Table 1 also shows the linear fits $\left(\mathrm{R}^{2}\right)$ and standard deviations (SD) obtained from the correlations between the ${ }^{13} \mathrm{C}$ NMR data of 2 and HF/6-31G* calculated carbon chemical shifts of $\mathbf{2}$ and its configurational derivatives for optimized geometries in the same level of theory. Correlations for $\mathbf{2}$ show the highest $\mathrm{R}^{2}(0.9971)$ and lowest SD (3.89) values (see Fig. 3). The plots of the carbonyl $\left(\delta_{\mathrm{C}} 205.0 ; \mathrm{C}-11\right)$ and alkenyl $\left(\delta_{\mathrm{C}} 146.3\right.$ and 112.8 , for $\mathrm{C}-14$ and $\mathrm{C}-15$, respectively) groups show higher deviations in relation to a linear fit curve. These deviations may be attributed to interactions between the solvent and $\pi$-systems that were not considered in the theoretical calculations [22].

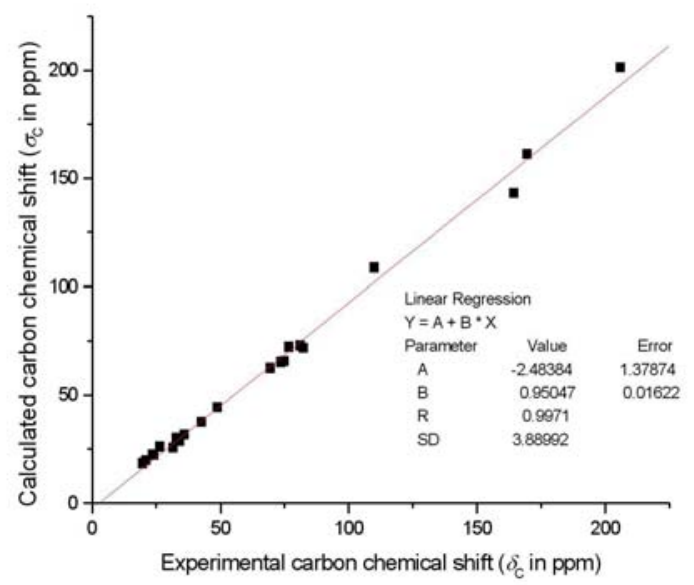

Fig. (3). Correlations between ${ }^{13} \mathrm{C}$ NMR data of 2 and HF/6-31G* calculated carbon chemical shifts of 2 (structure in the gaseous phase).

Thus, the best correlations are verified between the experimental ${ }^{13} \mathrm{C}$ NMR data of 2 and $\mathrm{HF} / 6-31 \mathrm{G}^{*}$ calculated carbon chemical shifts of $\mathbf{2}$, which agree with the structure proposed in the literature. As a consequence, this procedure may also be considered valid to determine the configuration of the labdane diterpenoid isolated from $P$. ornatus. Similar theoretical investigations were performed for $\mathbf{1}$ and its six corresponding configurational derivatives, i.e. 1(C7), 1(C8),
1(C13), 1(C7,C13), 1(C8,C13), and 1(C7,C8,C13), as shown in Fig. (2).

$\mathrm{HF} / 6-31 \mathrm{G}^{*}$ geometry optimizations and carbon chemical shift calculations were performed for $\mathbf{1}$ and its configurational derivatives. The conformational analyses of these structures are similar to those of $\mathbf{2}$ and its derivatives. Ring A and $\mathrm{B}$ are in chair conformations in all structures. The energy difference between the chair and the boat conformations of ring $\mathrm{A}$ is high $\left(\Delta E=E_{\text {(chair) }}-E_{\text {(boat) }} \sim-14.0 \mathrm{kcal} / \mathrm{mol}\right)$. Structures 1, 1(C7), 1(C13), and $1(\mathbf{C 7 , C 1 3 )}$ present ring C in a chair conformation. For these structures, the energy difference between the chair and the boat conformations of ring $\mathrm{C}$ is small $\left(\Delta E=E_{\text {(chair) }}-E_{\text {(boat) }}<-1.0 \mathrm{kcal} / \mathrm{mol}\right)$. On the other hand, ring $C$ of $\mathbf{1}(\mathrm{C8}), \mathbf{1}(\mathbf{C 8 , C 1 3})$, and $\mathbf{1}(\mathrm{C} 7, \mathrm{C8}, \mathrm{C13})$ is in a boat conformation. The energy difference between the chair and the boat conformations of ring $\mathrm{C}$ of the latter is high $\left(\Delta E=E_{\text {(boat) }}-E_{\text {(chair) }} \sim-22.0 \mathrm{kcal} / \mathrm{mol}\right)$.

Table 2 shows HF/6-31G* calculated energies $(E)$ of the optimized geometries of $\mathbf{1}$ and its configurational derivatives. 1(C8,C13) and 1(C8) show the lowest and the highest energies, respectively. The energy difference between these structures $\left(\Delta E=E_{\mathbf{1}(\mathbf{C 8}, \mathbf{C 1 3})}-E_{\mathbf{1}(\mathbf{C 8})}=-25.88 \mathrm{kcal} / \mathrm{mol}\right)$ is sufficiently high to favor mainly the formation of $\mathbf{1}(\mathbf{C 8}, \mathrm{C13})$. However this structure shows cis-fusion for rings $\mathrm{B} / \mathrm{C}$ with C-17 and C-14 on opposite sides of ring $\mathrm{C}$ plane ( $\alpha$ - and $\beta$ positions, respectively). This geometry does not allow the NOESY correlation to be observed between $\mathrm{H}-17$ and $\mathrm{H}-14$, which has been experimentally observed for the labdane diterpenoid isolated from $P$. ornatus.

Correlations between the experimental ${ }^{13} \mathrm{C}$ NMR data of the labdane diterpenoid isolated from $P$. ornatus and HF/6$31 \mathrm{G}^{*}$ calculated carbon chemical shifts of $\mathbf{1}$ and its configurational derivatives were obtained for optimized geometries in the same level of theory (Table 2). Correlations for 1(C13) show the highest $R^{2}(0.9993)$ and the lowest SD (2.09) values (as shown in Fig. 4). The stereochemistry of 1(C13) shows C-13 in the $S$ configuration and agrees with the NOESY correlation between the signal of H-16 only with the signal of H-14 observed for the labdane diterpenoid isolated from $P$. ornatus [2].

Moreover, this compound also shows a correlation between the signals of $\mathrm{H}-12$ and $\mathrm{H}-17$ in the NOESY contour map. The boat conformation of ring $\mathrm{C}$ was previously pro- 
Table 2. Electronic-Nuclear Energies $(E)$ of the Optimized Geometries of 1 and its Configurational Derivatives, Including Values of Linear Fit $\left(\mathbf{R}^{2}\right)$ and Standard Deviation (SD) Obtained for the Correlations Between ${ }^{13} \mathrm{C}$ NMR Data of the Labdane Diterpenoid Isolated from P. ornatus and their Calculated Carbon Chemical Shifts (HF/6-31G* Calculations Performed for Structures in the Gaseous Phase)

\begin{tabular}{|c|c|c|c|}
\hline Structure & $\boldsymbol{E}$ (in Hartree) & $\mathbf{R}^{2}$ & SD \\
\hline \hline $\mathbf{1}$ & -1605.59146801 & 0.9990 & 3.48 \\
\hline $\mathbf{1}(\mathbf{C 7})$ & -1605.60387157 & 0.9983 & 3.82 \\
\hline $\mathbf{1}(\mathbf{C 8})$ & -1605.58344451 & 0.9977 & 2.09 \\
\hline $\mathbf{1}(\mathbf{C 1 3})$ & -1605.59510402 & 0.9993 & 3.19 \\
\hline $\mathbf{1}(\mathbf{C 7 , C 1 3 )}$ & -1605.60784949 & 0.9984 & 4.13 \\
\hline $\mathbf{1}(\mathbf{C 8 , C 1 3 )}$ & -1605.62468041 & 0.9973 & 4.40 \\
\hline $\mathbf{1}(\mathbf{C 7 , C 8 , C 1 3 )}$ & -1605.62211270 & 0.9969 & \\
\hline
\end{tabular}

posed to justify this NOESY correlation for the forskolintype skeleton [9]. However, the crystal structure of forskolin derivatives indicates that ring $\mathrm{C}[9]$ is in the chair conformation. In the case of $\mathbf{1}(\mathbf{C 1 3})$, the calculated distances between $\mathrm{H}-17$ and $\mathrm{H}-12_{\beta}$ are 1.759 and $3.415 \AA$ for the boat and chair conformations, respectively. Therefore, both conformations of ring $\mathrm{C}$ of $\mathbf{1}(\mathrm{C13})$ allow NOESY correlations involving $\mathrm{H}-$ 17 and $\mathrm{H}-12_{\beta}$. In addition, these conformations of ring $\mathrm{C}$ may equally exist for $\mathbf{1}(\mathbf{C 1 3})$ in solution, considering the low calculated energy difference $\left(\Delta E=E_{\text {(chair) }}-E_{\text {(boat) }}<-1.0\right.$ $\mathrm{kcal} / \mathrm{mol})$. Thus, the correct relative stereochemistry of the labdane diterpenoid isolated from $P$. ornatus is $\mathbf{1}(\mathbf{C}-\mathbf{1 3})$, as shown in Fig. (2).

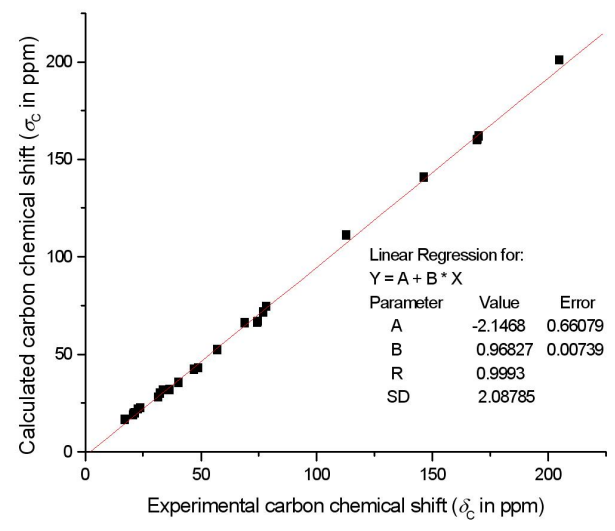

Fig. (4). Correlations between ${ }^{13} \mathrm{C}$ NMR data of the labdane diterpenoid isolated from $P$. ornatus and $\mathrm{HF} / 6-31 \mathrm{G}^{*}$ calculated carbon chemical shifts of $\mathbf{1}(\mathbf{C 1 3})$ (structure in the gaseous phase).

The DFT/BLYP/6-31G* method was also employed in geometry optimizations and calculations of carbon chemical shifts. The energy and chemical shift values calculated by the DFT/BLYP/6-31G* method agree with the HF/6-31G* calculated values. These values are shown as supplementary material.

\section{CONCLUSION}

Theoretical investigations on the chemical properties of organic compounds have grown quickly in the last years.
However, relatively few works have employed theoretical calculations of NMR data to investigate configurational analysis of organic compounds. Initially, correlations between ${ }^{13} \mathrm{C}$ NMR data of forskolin and calculated carbon chemical shifts of forskolin (2) and six different forskolintype structures were performed. The best correlations were verified between ${ }^{13} \mathrm{C}$ NMR data of 2 and $\mathrm{HF} / 6-31 \mathrm{G}^{*}$ calculated carbon chemical shifts of 2 . Thus, this procedure was considered valid to determine the relative configuration of the labdane diterpenoid isolated from $P$. ornatus.

Among the different structures investigated, the ${ }^{13} \mathrm{C}$ NMR data of the labdane diterpenoid isolated from $P$. ornatus showed the best correlation with 1(C13). The stereochemistry of this structure is an epimer of the structure previously proposed (1). In contrast, 1(C13) shows configurational inversion at $\mathrm{C}-13$ ( $S$ configuration) in relation to $\mathbf{1}$ (with $R$ configuration of $\mathrm{C}-13$ ). Thus, carbon chemical shift calculations may be an efficient alternative for the configurational and conformational analyses of organic compounds, mainly when experimental data are insufficient or do not exist.

\section{ACKNOWLEDGEMENTS}

The authors thank Conselho Nacional de Desenvolvimento Científico e Tecnológico (CNPq), Fundação Coordenação de Aperfeiçoamento de Pessoal de Nível Superior (CAPES), and Fundação de Amparo à Pesquisa do Estado de Minas Gerais (FAPEMIG) for the financial support.

\section{SUPPLEMENTARY MATERIAL}

Supplementary material can be viewed at www.bentham.org/open/tonpj

\section{REFERENCES}

[1] Albuquerque, R.L.; Kentopff, M.R.; Machado, M.I.; Silva, M.G.V.; Matos, F.J.A. Diterpenos tipo abietanos isolados de Plectranthus barbatus andrews. Quim. Nova, 2007, 30(8), 1882-1886.

[2] Oliveira, P.M.; Ferreira, A.A.; Silveira, D.; Alves, R.B.; Rodrigues, G.V.; Raslan, D.S. Diterpenoids from the aerial parts of Plectranthus ornatus. J. Nat. Prod., 2005, 68(4), 588-91.

[3] Rijo, P.; Simões, M.F.; Rodríguez, B. Structural and spectral assignment of three forskolin-like diterpenoids isolated from Plectranthus ornatus. Magn. Res. Chem., 2005, 43(7), 595-8. 
[4] Rijo, P.; Gaspar-Marques, C.; Simões, M.F.; Duarte, A.; Rodríguez, B. Neoclerodane and labdane diterpenoids from Plectranthus ornatus. J. Nat. Prod., 2002, 65(10), 1387-90.

[5] Lukhoba, C.W.; Simmonds, M.S.J.; Paton, A.J. Plectranthus: a review of ethnobotanical uses. J. Ethnopharmacol., 2006, 103, $1-24$.

[6] Shan, Y.; Xu, L.; Lu, Y.; Wang, X.; Zheng, Q.; Kong, L.; Niwa, M. Diterpenes from Coleus forskohlii (Willd.) Briq. (Labiatae). Chem. Pharm. Bull., 2008, 56(1), 52-56.

[7] Shan, Y.; Wang, X.; Zhou, X.; Kong, L.; Niwa, M. Two minor diterpene glycosides (I) and an eudesmane sesquiterpene (II) from Coleus forskohlii. Chem. Pharm. Bull., 2007, 55(3), 376-381.

[8] Xu, L.-L.; Kong, L.-Y. Labdane diterpenoids from Coleus forskohlii (Willd.) Briq. J. Integr. Plant Biol., 2006, 48(4), 478-81.

[9] Roy, R.; Misitra, A.; Varma, N.; Tandon, J.S.; Saux, M.; Carpy, A. Minor diterpenes from Coleus forskohlii. Phytochemistry, 1993, 34(6), 1577-80.

[10] Binkley, J.S.; Pope, J.A.; Hehre, W.J. Self-consistent molecular orbital methods. 21. Small split-valence basis sets for first-row elements. J. Am. Chem. Soc., 1980, 102(3), 939-47.

[11] Parr, R.G.; Yang, W. Density Functional Theory of Atoms and Molecules; Oxford: New York, 1989.

[12] Santos, F.J.L.; Alcântara, A.F.C.; Piló-Veloso, D. Theoretical and experimental NMR studies of the Swern oxidation of methyl $6 \alpha, 7 \beta$ dihydroxyvouacapan-17 $\beta$-oate. Struct. Chem., 2008, 19, 625-31.

[13] Alcântara, A.F.C.; Piló-Veloso, D.; Almeira, W.B.; Maltha, C.R.A.; Barbosa, L.C.A. Conformational analysis of 8oxabicyclo[3.2.1] oct-6-en-3-one derivatives by NMR and theoretical calculations. J. Mol. Struct., 2006, 791, 180-5.

[14] Pérez-Rebolledo, A.; Mendes, I.C.; Speziali, N.L.; Bertani, P.; Resende, J.M.; Alcântara, A.F.C.; Beraldo, H. N(4)-methyl-4nitroacetophenone thiosemicarbazone and its nickel(II) complex: experimental and theoretical structural studies. Polyhedron, 2007, $26,1449-58$

[15] Frisch, M.J.; Trucks, G.W.; Schlegel, H.B.; Scuseria, G.E.; Robb, M.A.; Cheeseman, J.R.; Montgomery, J.A.; Vreven, T.; Kudin, K.N.; Burant, J.C.; Millam, J.M.; Iyengar, S.S.; Tomasi, J.; Barone, V.; Mennucci, B.; Cossi, M.; Scalmani, G.; Rega, N.; Petersson, G.A.; Nakatsuji, H.; Hada, M.; Ehara, M.; Toyota, K.; Fukuda, R.;
Hasegawa, J.; Ishida, M.; Nakajima, T.; Honda, Y.; Kitao, O.; Nakai, H.; Klene, M.; Li, X.; Knox, J.E.; Hratchian, H.P.; Cross, J.B.; Adamo, C.; Jaramillo, J.; Gomperts, R.; Stratmann, R.E.; Yazyev, O.; Austin, A.J.; Cammi, R.; Pomelli, C.; Ochterski, J.W.; Ayala, P.Y.; Morokuma, K.; Voth, G.A.; Salvador, P.; Dannenberg, J.J.; Zakrzewski, V.G.; Dapprich, S.; Daniels, A.D.; Strain, M.C.; Farkas, O.; Malick, D.K.; Rabuck, A.D.; Raghavachari, K.; Foresman, J.B.; Ortiz, J.V.; Cui, Q.; Baboul, A.G.; Clifford, S.; Cioslowski, J.; Stefanov, B.B.; Liu, G.; Liashenko, A.; Piskorz, P.; Komaromi, I.; Martin, R.L.; Fox, D.J.; Keith, T.; Al-Laham, M.A.; Peng, C.Y.; Nanayakkara, A.; Challacombe, M.; Gill, P.M.W.; Johnson, B.; Chen, W.; Wong, M.W.; Gonzalez, C.; Pople, J.A. GAUSSIAN, Revision B.04; Gaussian, Inc.: Pittsburgh PA, 2003.

[16] Dewar, M.J.S.; Zoebish, E.G.; Healy, E.F.; Stewart, J.J.P. Development and use of quantum mechanical molecular models. 76. AM1: a new general purpose quantum mechanical molecular model. J. Am. Chem. Soc., 1985, 107(13), 3902-9.

[17] Ditchfield, R.; Hehre, W.J.; Pople, J.A. Self-consistent molecularorbital methods. IX. An extended gaussian-type basis for molecular-orbital studies of organic molecules. J. Chem. Phys., 1971, 54(2), 724-8

[18] Hehre, W.J.; Ditchfield, R.; Pople, J.A. Self-consistent molecular orbital methods. XII. Further extensions of gaussian-type basis sets for use in molecular orbital studies of organic molecules. $J$. Chem. Phys., 1972, 56(5), 2257-61.

[19] Hariharan, P.C.; Pople, J.A. Accuracy of $\mathrm{AH}_{n}$ equilibrium geometries by single determinant molecular orbital theory. Mol. Phys. 1974, 27(1), 209-14

[20] Gordon, M.S. The isomers of silacyclopropane. Chem. Phys. Lett., 1980, 76(1), 163-8.

[21] Hariharan, P.C.; Pople, J.A. The influence of polarization functions on molecular orbital hydrogenation energies. Theor. Chim. Acta, 1973, 28(3), 213-22.

[22] Alcântara, A.F.C.; Teixeira, A.F.; Silva, I.F.; Piló-Veloso, D; Almeida, W.B. NMR Investigation and Calculation of the effect of solvent on the conformational analysis of 4',7-di-hydroxy-8prenylflavan. Quim. Nova, 2004, 27(3), 371-7.

(C) Oliveira et al.; Licensee Bentham Open.

This is an open access article licensed under the terms of the Creative Commons Attribution Non-Commercial License (http://creativecommons.org/licenses/by-nc/3.0/) which permits unrestricted, non-commercial use, distribution and reproduction in any medium, provided the work is properly cited. 